\title{
DESIGN OF RISK SHARING AND COORDINATION MECHANISM IN SUPPLY CHAIN UNDER DEMAND AND SUPPLY UNCERTAINTY
}

\author{
Chunyi Ji*i) And XiangXiang LiU
}

\begin{abstract}
Perishable and short-life products can be seen everywhere in life. Due to the particularity of these products, they are more complicated in supply chain management. This paper studies whether the two-part tariff and ZRS contract can achieve the purpose of reducing risks and coordinating supply chain. We assume that market demand and supplier yield are uncertain, and we use game theory and probability distribution for research. The research results show that when the information is asymmetric, the manufacturer always ignore the demand forecast information provided by the retailer under the wholesale price contract. When the demand is uncertain, regardless of whether the information is symmetric or asymmetric, the two-part tariff contract and the ZRS contract can coordinate the supply chain and achieve maximum profit. When the retailer's degree of risk aversion is high, the ZRS contract is better than the two-part tariff, which can reduce the risk of retailers and achieve the purpose of coordinating the supply chain. When the supply is uncertain, the manufacturer can provide the supplier with a risk-sharing contract, including the return price and the sharing ratio that meet certain constraints. Such a contract can effectively reduce the supplier's risk and realize supply chain coordination.
\end{abstract}

Mathematics Subject Classification. 90B06.

Received April 30, 2021. Accepted December 16, 2021.

\section{INTRODUCTION}

In daily life, there are many perishable products with short shelf life, such as bread, cakes, fresh milk, etc. The production preparation period for these products is longer, while the sales period is shorter. Due to a long production lead time, the retailer places an order in advance of the selling season and the supplier begins production after receiving the order. All the risks from stochastic demand and inventory are pushed onto the retailer. In recent years, the problems of uncertain demand and uncertain yield have also received extensive attention from many researchers. With the rapid development of society, increasingly fierce competition in the industry, rapid technological progress, increased consumer expectations and shortened product life cycles, the demand for products has become more variable than ever before $[4-6,11]$. Random yield problem can be seen everywhere in daily life, because some unpredictable events will occur in the production process, such as machine failure or immature technology, and a certain amount of input may produce an uncertain yield $[13,21,29,31]$. The problem of uncertain demand and random yield not only brings difficulties to the decision-making in the supply

Keywords. Risk sharing, supply chain coordination, information asymmetry, uncertainty of yield and demand.

School of Business, Jiangnan University, Wuxi, P.R. China.

*Corresponding author: jcynfu@gmail.com 
chain, but also causes some risks to the supply chain. Such problem is more obvious in the supply chain that produces products that are perishable and have a short shelf life, such as bread, cakes, fresh milk, etc. Retailers and suppliers in this supply chain bear the risks from uncertain demand and uncertain yield respectively.

In this case, these supply chain members always make unilateral decisions based on their own interests. However, unilateral decisions rarely conform the best interests of the whole system, resulting in a double marginal effect. Supply chain coordination brings a new philosophy, which aims to adjust the motivations of various channel members and coordinate their decisions and activities to achieve the optimal supply chain. To achieve supply chain coordination, many experts have conducted extensive research on various price contracts, such as quantity discount contract, revenue sharing contract, buyback contract and two-part tariff contract, etc. These research results show that through these contracts, supply chain members can utilize the vertical integration of the supply chain to flexibly allocate the maximum profits of the supply chain participants. The two-part tariff contract has been widely discussed in the context of the vertical coordination of the supply chain. It not only reduces the double marginal effect of the supply chain, but also realize the vertical integration of the supply chain [22]. In recent years, there has been an interesting emergence and discussion of zero wholesale price (ZWP)-based contracts for perishable and short-life products [25,36]. Based on the ZWP contract, Choi [7] proposes the ZWP-revenue-sharing-plus-side-payment contract (ZRS contract). The research results show that this ZRS contract can increase the profits of both parties and realize the coordination of supply chain.

In the research of supply chain coordination, market demand information also plays an important role. When the information is symmetrical, both manufacturers and retailers know the distribution function of market demand [8]. The reason for the information asymmetry is that retailers sell goods directly to consumers, so retailers have the advantage of obtaining consumer demand data better than manufacturers. When retailers have private forecast information, they may falsely report their private forecast information to obtain more profits. Ineffective information sharing does harm the interests of the collective. Egri and Váncza [9] pointed out that designing suitable coordination contracts under asymmetric information is one of the most pressing challenges of supply chain management.

In this paper, a three-level supply chain that produces perishable products with short shelf life is considered. In this supply chain, manufacturer acts as the leader, and retailer and supplier bear the risk of uncertain demand and supply, respectively. Uncertainty not only brings risks to the supply chain, but also causes retailers and suppliers to make decisions based on their own interests, resulting in uncoordinated supply chains. Therefore, we need to design contracts to reduce the risks of retailers and suppliers and achieve supply chain coordination. First, in the case of uncertain demand, we study how manufacturers can use contracts to reduce the risk of retailers when demand information is symmetrical or asymmetrical. Based on the wholesale price contract, we use probability distribution methods and game theory methods to study the coordination effect of the twopart tariff contract and the ZRS contract on the supply chain. The two contracts can achieve supply chain coordination and reduce the risk of retailers. In the case of uncertain supply, the supplier's yield may meet the manufacturer's order or may not meet. When the production is insufficient, the supplier need procures production from other markets. When the production is excessive, the supplier cannot store them for a long time, resulting in a waste of resources. Hence, we design a risk-sharing contract. And the research results show that this contract reduce the supplier's risk and coordinate the entire supply chain. Finally, we use numerical analysis to demonstrate the above research and give the corresponding management significance.

\section{Literature REVIEW}

It has been widely studied to achieve supply chain coordination through various price contracts. Zhang and Chen [35] pointed out that both the double marginal effect and the bullwhip effect reduce the efficiency and effectiveness of the supply chain. Supply chain contracts can ensure cooperation and coordination among members in decision-making and sharing of demand information, which is an effective way to reduce the bullwhip effect. Pasternack [24] proposed a buyback contract: suppliers sell products to retailers at wholesale price, recycle products that the retailer have not sold after the sale ends at a fixed unit price. Pasternack proved that if the 
TABLE 1. Overview of literature reviews.

\begin{tabular}{lllllll}
\hline \hline Literature & $\begin{array}{l}\text { Yield } \\
\text { uncertainty }\end{array}$ & $\begin{array}{l}\text { Demand } \\
\text { uncertainty }\end{array}$ & $\begin{array}{l}\text { Information } \\
\text { asymmetry }\end{array}$ & $\begin{array}{l}\text { Two-part } \\
\text { tariff contract }\end{array}$ & $\begin{array}{l}\text { ZRS } \\
\text { contract }\end{array}$ & $\begin{array}{l}\text { Risk-sharing } \\
\text { contract }\end{array}$ \\
\hline $\begin{array}{l}\text { Choi and Guo [36] } \\
\text { Li and Luo [6] }\end{array}$ & & $\sqrt{ }$ & & $\sqrt{ }$ & $\sqrt{ }$ & \\
Li and Liu [35] & & $\sqrt{ }$ & $\sqrt{ }$ & & & $\sqrt{ }$ \\
Li and Chen [26] & & $\sqrt{ }$ & $\sqrt{ }$ & $\sqrt{ }$ & & \\
Ye and Lin [4] & $\sqrt{ }$ & $\sqrt{ }$ & & $\sqrt{ }$ & & \\
Yan and Chen [20] & & $\sqrt{ }$ & $\sqrt{ }$ & & & \\
Giri [13] & $\sqrt{ }$ & $\sqrt{ }$ & & & $\sqrt{ }$ \\
Adhikar and Bisi [1] & $\sqrt{ }$ & $\sqrt{ }$ & & $\sqrt{ }$ & $\sqrt{ }$ \\
This paper & $\sqrt{ }$ & $\sqrt{ }$ & $\sqrt{ }$ & $\sqrt{ }$ & & \\
\hline
\end{tabular}

wholesale price and the repurchase price are appropriately selected, then the buyback contract can achieve supply chain coordination. Inspired by the video rental market, Cachon and Lariviere [2] proposed a revenue sharing contract: the retailer pays the supplier a wholesale price for each unit of the product sold, plus a percentage of the retailer's revenue. When the wholesale price and income sharing ratio meet certain conditions, the revenue sharing contract can also coordinate the supply chain. Both the buyback contract and the revenue-sharing contract distribute profits arbitrarily between suppliers and retailers. Some studies have shown that two-part tariff contract can be more effective than the wholesale price contracts $[3,10,23]$. Under certain conditions, two-part tariff contract is more beneficial to manufacturers than quantity discount contracts $[17,26]$. In recent years, zero wholesale price (ZWP) contracts applicable to perishable and short-lived products have received extensive attention and discussion $[25,36]$. ZWP-based contracts are attractive to retailers because the low cost of obtaining products reduces the risks associated with purchasing. Choi and Guo [7] made improvements based on the ZWP contract and proposed the ZWP-revenue-sharing-plus-side-payment contract (referred to as the ZRS contract). They pointed out that the ZRS contract can achieve win-win coordination, in which the supply chain is optimized, and both manufacturers and retailers benefit from the implementation of the contract. We study how to achieve the coordination of the supply chain by using two-part tariff contract and ZRS contracts compared with wholesale price contracts in a three-level supply chain.

At present, many scholars have conducted extensive research on the uncertainty of demand and yield in the supply chain. Inderfurth and Clemens [14] pointed out that both parties are exposed to risks of overproduction or under-delivery, respectively, if a simple wholesale price contract is applied. So they studied how to design a risk-sharing contract to coordinate the supply chain under the conditions of demand determination and random yield. Xie and Ma [32] investigate the buyback contract for the supply chain and studies how the yield uncertainty and the relative bargaining power affect the performance of buyback contract. Their results suggest that when the seller's bargaining power is relatively high and can control the uncertain yield, the buyback contract is sufficient to coordinate the supply chain. Tang and Kouvelis [29] considered whether the buyback-revenue sharing contract can coordinate the supply chain when the yield is random and the demand is determined and uncertain. They show how a specially designed contract, such as a buyback-revenue sharing contract, can coordinate the supply chain and mention its probable application in the agribusiness scenario. Uncertain demand and random yield are the main reasons for supply chain risks. Many scholars have paid great attention to supply chain risks and uncertainties $[27,28,30]$. They all indicate that the risks caused by uncertain demand or yield are not conducive to supply chain management, and mechanisms need to be designed to reduce risks. This paper comprehensively considers the uncertain demand and random yield in the supply chain for research, and on this basis, designs a risk-sharing contract to reduce risks and coordinate the supply chain.

As far as we know, there are some papers related to this one. To compare with related literature and better display our contributions, we list them in Table 1. 
$\mathrm{Li}$ and Liu [18] started from the two situations of demand information symmetry and information asymmetry, and studied how to design contracts in the newsvendor model, which can not only meet the two characteristics of incentive compatibility and individual rationality, but also achieve the purpose of coordinating the supply chain. However, their study did not consider the uncertain production and demand situation. Therefore, this paper considers whether the two-part tariff contract can still coordinate the supply chain under the uncertainty of supply and demand. Giri [12] considers a newsvendor model for a single product to focus on the importance of coordination under demand and supply uncertainties where the raw materials are procured from two unreliable suppliers (the main supplier and the backup supplier) without any emergency resource. They propose the price only contract and a new revenue sharing contract to mitigate demand and supply uncertainties in the decentralized model, and observe that the revenue sharing contract can fully coordinate the supply chain with win-win outcome for all entities involved in the supply chain. In our paper, we have also studied the uncertainty of supply and demand, but we only have one supplier, and his yield is also random. We assume that when his output is insufficient, he needs to buy at high prices from other markets to ensure delivery. Then, in response to this situation, we also designed a new risk-sharing contract to coordinate the supply chain.

Adhikar and Bisi [1] studied whether a coordination mechanism can be used for risk sharing and risk aversion in a five-level textile supply chain under the conditions of demand and supply uncertainty. When manufacturers dominate the supply chain, buyback contracts are used, and when retailers dominate the supply chain, option contracts are used. Their research results show that wholesale price contracts cannot coordinate the supply chain, while the use of buyback contracts and option contracts can coordinate the supply chain, and risksharing contract can also reduce risks and coordinate the supply chain. We studied a three-level supply chain with perishable production and short shelf life. Like them, we also considered the situation of uncertain yield and demand. In addition, we also considered two situations of demand information symmetry and information asymmetry. And we use two-part tariff contract and ZRS contract to coordinate and research the supply chain.

In general, some papers have considered the uncertainty of yield and demand, and chose contracts or design mechanisms to coordinate the supply chain. However, no paper comprehensively considers the uncertain demand and random yield to study the risk sharing and coordination of the supply chains of perishable and short-lived products. This paper creatively studies the problem of uncertainty in yield and demand in a specific supply chain (a three-level supply chain that produces perishable products with short shelf life). And we use two-part tariff contract and ZRS contract, as well as design risk-sharing contract to coordinate the supply chain.

\section{Model DESCRIPTIONS}

This paper studies how in a three-level supply chain, when the yield is random and the demand is uncertain, how large-scale, risk-resistant manufacturers can coordinate the supply chain through price contracts and help suppliers and retailers to share risk. This three-tier supply chain is composed of a supplier $(S)$ who provides raw materials, a manufacturer $(M)$ who manufactures products, and a retailer $(R)$ who sells products. The products produced by this supply chain are perishable and short-lived, such as fresh milk, bagged yogurt, cakes in cake shops and other products. These products need to be sold within a short period of time after they are completed, otherwise they must be discarded at a cost. We assume that manufacturers are risk-neutral, while suppliers and retailers are risk-averse.

The decision-making mechanism of each member of this three-level supply chain is as follows: the actual consumer demand for this type of product is $X$, which obeys the cumulative distribution function $F(x)$ and the probability density function $f(x)$. The retailer's retail price is $p$, and his order quantity $Q_{R}$ is determined according to the market demand function (see Tab. 2). If there are products remaining after the retailer's sales period ends, the management cost per unit of product is $h$. The manufacturer decides its own order quantity $Q_{M}$ according to the retailer's order quantity, where $Q_{M}=k * Q_{R}$, its production cost is $C_{M}$, and the wholesale price is $W_{M}$. The supplier decides the planned yield $Q_{S}$ according to the manufacturer's order quantity $Q_{M}$, and its production cost is $C_{S}$, and its wholesale price is $W_{S}$. The supplier's yield is random, then the yield can be expressed by $Z Q_{S}$ [17]. The yield rate $Z$ is a non-negative random variable with range [0,1], and it obeys the 
TABLE 2. Description of the decision variables, parameters, and the corresponding notations.

\begin{tabular}{ll}
\hline \hline Decision variables & Notation \\
\hline Wholesale price of the manufacturer & $W_{M}$ \\
Wholesale price of the manufacturer in the two-part tariff contract & $W_{M}^{T}$ \\
Wholesale price of the supplier & $W_{S}$ \\
Wholesale price of the supplier in the risk-sharing contract & $W_{S}^{\prime}$ \\
Order quantity of the retailer & $Q_{R}$ \\
Order quantity of the manufacturer & $Q_{M}$ \\
Planned production quantity of the supplier & $Q_{S}$ \\
\hline Parameters & Notation \\
\hline Retail price per unit of the retailer & $p$ \\
Management cost per unit of the retailer & $h$ \\
Production cost per unit of the manufacturer & $C_{M}$ \\
Production cost per unit of the supplier & $C_{S}$ \\
Purchase cost per unit from other market & $C_{S}^{\prime}$ \\
Revenue sharing ratio under the ZRS contract & $\alpha$ \\
Payback price of the manufacturer in the risk-sharing contract & $b$ \\
Share ratio of the manufacturer in the risk-sharing contract & $\beta$ \\
Fixed fee in the two-part tariff contract & $F$ \\
Additional fee in the ZRS contract & $S$ \\
\hline
\end{tabular}

cumulative distribution function $T(x)$, the probability density function is $t(x)$. The expected value of the yield $Z$ be represented as $\mu(0<\mu<1)$. Suppliers may have insufficient production or excessive production when providing raw materials for manufacturer. When the production is insufficient, the supplier procures production from other markets at the cost of $C_{S}^{\prime}$. When the production is excessive, the supplier cannot store them for a long time, resulting in a waste of resources. The above is the operating mechanism of this three-level supply chain.

Due to uncertain demand information, random yield, and different risks, each entity always makes decisions based on its own interests, which ultimately leads to in-coordination of the supply chain. In response to the problems in this supply chain operation mechanism, the manufacturer provides retailers with ZRS contract $(S)$ and two-part tariff $(T)$ contract to coordinate the supply chain and provide the supplier with risk-sharing contract (RS). The ZRS contract means that after the retailer completes the sale, it shares the revenue with the manufacturer with the revenue ratio $\alpha$, and the manufacturer charges the retailer an additional fee $S$. The two-part tariff contract has a unit wholesale price $W_{M}^{T}$ and fixed fee $F$. The revenue sharing contract is to provide a unit buyback ratio $b$ to repurchase excess raw materials when the supplier's output is too high, and when the supplier's output is low, the manufacturer provides a cost sharing ratio $\beta$. Without loss of generality, we assume $W_{M}^{T}<W_{M}$.

Three different contracts are examined in this study, namely, two-part tariff contract, ZRS contract and risksharing contract. We aim to investigate the following problems: (1) When demand information is symmetrical and asymmetrical, are both the two-part tariff contract and the ZRS contract better than wholesale contracts? (2) Does a unique equilibrium exist in the Stackelberg game for three contracts? (3) What condition can coordinate the supply chain in the three contracts? (4) What is the benefit of our proposed contracts? 


\section{UNCERTAINTY OF YIELD AND DEMAND}

\subsection{Demand uncertainty}

\subsubsection{Symmetry of demand information}

In the case of information symmetry, the manufacturer and the retailer can observe each other decisionmaking information and they have the same market demand information. For example, for the Chinese cake chain Hollyland, its manufacturers and retailers are managed by Hollyland, and all the demand information obtained by the retailer will be shared with the manufacturer. Here we assume that the market demand is uncertain, and the market demand obeys a random distribution $F(x)$, the probability density function is $f(x)$. We assume that the supplier and the manufacturer adopt wholesale price contracts, and the manufacturer and the retailer also adopt wholesale price contracts $(W)$. Below we will mainly study whether the manufacturer provides the retailer with the ZRS contract $(Z)$ and two-part tariff contract $(T)$ to coordinate the supply chain. Among them, the ZRS contract refers to a three-part combination of zero wholesale price, revenue sharing and additional costs.

When this supply chain makes a centralized decision, the expected profit function of the entire supply chain is as follows:

$$
\Pi_{\mathrm{SC}}=p E \min \left(Q_{R}, X\right)-h E \max \left(Q_{R}-X, 0\right)-C_{M} Q_{R}-C_{S} Q_{S}-C_{S}^{\prime} E\left(Q_{M}-Z Q_{S}\right)^{+} .
$$

This function expression is a concave function, there is a unique $Q_{R}$, which maximizes the expected profit of the supply chain. We can obtain the following equation through the first derivative of the above expression:

$$
p-C_{M}-(p+h) F\left(Q_{R}^{\mathrm{SC}}\right)-\frac{k C_{S}^{\prime}}{Q_{S}} T\left(\frac{k Q_{R}^{\mathrm{SC}}}{Q_{S}}\right)=0 .
$$

The above equation shows that the uncertainty of demand and supply plays a crucial role in determining the optimal order quantity of products and the optimal planned production quantity of raw materials. In addition, the increase in the production costs of manufacturers and the procurement costs of suppliers in the spot market will reduce the order volume of products and the planned yield of raw materials.

The retailer's expected profit function under the wholesale price contract is as follows:

$$
\Pi_{R}^{W}=p E_{x} \min \left(Q_{R}, X\right)-h E_{x} \max \left(Q_{R}-X, 0\right)-W_{M} Q_{R} .
$$

This function expression is a concave function. So, there is a unique $Q_{R}$ to maximize the retailer's expected profit. We can obtain the following equation by seeking the first derivative of the above expression:

$$
Q_{R}^{W}=F^{-1}\left(\frac{p-W_{M}}{p+h}\right)
$$

In the wholesale price contract, the manufacturer is the leader of the game, it determines the wholesale price $W_{M}$, and then the retailer determines the order quantity $Q_{R}$. Here, to make the manufacturer profitable, we need to set $C_{M}<W_{M}<p$ and $Q_{R} \in(\underline{X}, \bar{X})$. According to (4.4), the manufacturer's optimal wholesale price can be written as:

$$
W\left(Q_{R}\right)=p-(p+h) F\left(Q_{R}\right) .
$$

The manufacturer's expected profit function is:

$$
\Pi_{M}^{W}=\left(W_{M}-C_{M}\right) Q_{R}-W_{S} Q_{M}=\left[p-(p+h) F\left(Q_{R}\right)-C_{M}\right] Q_{R}-W_{S} Q_{M} .
$$

Lariviere and Porteus [16] proved that when the demand distribution function $F(x)$ has an increasing generalized failure rate (IGFR) (when $F(x)<1, \frac{f(x) x}{\bar{F}(x)}$ is weakly increasing for all $x$ ). Then there is a unique $Q_{R}$ 
to maximize the manufacturer's profit. We obtain the following equation by taking the first derivative of the manufacturer's expected profit function, if the equation

$$
\frac{h+C_{M}+k W_{S}}{p+h}=\bar{F}\left(Q_{R}\right)\left(1-\frac{f\left(Q_{R}\right) Q_{R}}{\bar{F}\left(Q_{R}\right)}\right)
$$

there is an optimal solution when $Q_{R} \in(\bar{X}, \underline{X})$. Then the optimal solution of the order is $Q_{R}^{w}$, otherwise, the order quantity is $\underline{X}$.

Theorem 4.1. When the market demand is uncertain and the demand information is symmetric, the retailer's optimal order quantity under the wholesale price contract is smaller than the optimal order quantity of the supply chain when the centralized decision is made, that is, $Q_{R}^{W}<Q_{R}^{\mathrm{SC}}$. In other words, the wholesale price contract cannot achieve supply chain coordination.

For each member of the supply chain, the price of a unit commodity is always higher than the total production cost and purchase cost, i.e., $W_{M}>C_{M}+k W_{S}$. And the supplier's wholesale price is greater than the purchase cost, i.e., $W_{S}>C_{S}>C_{S}^{\prime}$. According to the actual situation, the supplier planned production $Q_{S}$ is an integer greater than 1, and the cumulative distribution function $T(x)$ of the production rate $Z$ is less than 1 , so $T\left(\frac{k Q_{R}^{\mathrm{SC}}}{Q_{S}}\right) / Q_{S}<1$. Then, we can know that $W_{M}>C_{M}+\frac{k C_{S}^{\prime}}{Q_{S}} T\left(\frac{k Q_{R}^{\mathrm{SC}}}{Q_{S}}\right)$ and $Q_{R}^{W}<Q_{R}^{\mathrm{SC}}$. In other words, the retailer's optimal order quantity in the wholesale price contract is less than the optimal order quantity of the supply chain, so this three-level supply chain does not achieve coordination in the wholesale price contract.

Therefore, this paper studies two-part tariff contract $(T)$ and ZRS contract $(Z)$ to prove whether they can coordinate the supply chain. The expected profit function of the retailer under these two contracts is as follows:

$$
\begin{aligned}
& \Pi_{R}^{Z}=(1-\alpha) p E_{x} \min \left(Q_{R}, X\right)-h E_{x} \max \left(Q_{R}-X, 0\right)-S \\
& \Pi_{R}^{T}=p E_{x} \min \left(Q_{R}, X\right)-h E_{x} \max \left(Q_{R}-X, 0\right)-w_{M}^{T} Q_{R}-F .
\end{aligned}
$$

Taking the first derivative of the expected profit function of the retailer under these two contracts, we can get their optimal order quantity $Q_{R}^{*}$, among them, $* \in(Z, T)$.

$$
\begin{aligned}
& Q_{R}^{Z}=F^{-1}\left(\frac{(1-\alpha) p}{(1-\alpha) p+h}\right) \\
& Q_{R}^{T}=F^{-1}\left(\frac{p-W_{M}^{T}}{p+h}\right) .
\end{aligned}
$$

Lemma 4.2. In the wholesale price contract, the optimal order quantity $Q_{R}^{W}$ is inversely proportional to the unit management cost $h$ and the manufacturer's wholesale price $W_{M}$. In the ZRS contract, the optimal order quantity $Q_{R}^{Z}$ is inversely proportional to the unit management cost $h$ and the revenue sharing ratio. In the twopart tariff contract, the optimal order quantity $Q_{R}^{T}$ is inversely proportional to the unit management cost $h$ and the manufacturer's wholesale price.

In these three contracts, the increase in the unit management cost $h$ of unsold products will make the retailer's order volume smaller. The reduction of retailers' orders will result in a reduction in the expected profit of the entire supply chain. Therefore, retailers should take relevant measures to reduce the value of management cost $h$, increase retailer's order demand, and then increase the profit of the entire supply chain. Comparing the wholesale price contract with the two-part tariff contract shows that when the manufacturer's wholesale price decreases, the retailer's order demand increases, which will increase the manufacturer's and the retailer's profits. Therefore, in the two-part tariff contract, the manufacturer should set a lower wholesale price not lower than the cost to obtain more orders and thus obtain more profits. In the ZRS contract, the lower the manufacturer's share of revenue to the retailer, the higher the retailer's demand. Therefore, the manufacturer should set a lower sharing ratio to increase the retailer's demand, and by charging an extra fee $S$ to ensure that their profits increase. 
Theorem 4.3. According to equations (4.4) and (4.6) and assumptions $W_{M}^{T}<W_{M}$, it can be obtained that the optimal order quantity under the two-part tariff contract is greater than the optimal order quantity under the wholesale contract, i.e., $Q_{R}^{T}>Q_{R}^{W}$. When $p$ and $h$ are constant and $\alpha<1-\frac{h\left(p-W_{M}\right)}{p\left(h+W_{M}\right)}$, it can be obtained that the optimal order quantity under the ZRS contract is greater than the optimal order quantity under the wholesale price contract, i.e., $Q_{R}^{Z}>Q_{R}^{W}$.

It can be seen from the above Theorem 4.3 that when $W_{M}^{T}<W_{M}$, the retailer's optimal order quantity under the two-part tariff contract is always greater than the optimal order quantity under the wholesale price contract. And, from Theorem 4.1, the optimal order quantity of the retailer in the supply chain under the centralized decision is greater than the optimal order quantity under the wholesale price contract. Therefore, as long as the manufacturer reasonably sets the wholesale price and fixed fee $F$ under the two-part tariff contract, not only can the retailer's profit be increased, but the profit of the entire supply chain can also be increased, thereby achieving the purpose of coordinating the supply chain.

In the wholesale price contract, the manufacturer's wholesale price $W_{M}$, retailer's sales price $p$, and processing $\operatorname{cost} h$ are all fixed values. When the manufacturer sets the revenue sharing ratio $\alpha$, when $\alpha$ satisfies the inequality $\alpha<1-\frac{h\left(p-W_{M}\right)}{p\left(h+W_{M}\right)}$, the retailer's optimal order quantity in the ZRS contract is greater than the optimal order quantity of the wholesale price contract. Therefore, setting a reasonable revenue sharing ratio $\alpha$ can increase the overall profits of retailers and the supply chain.

In general, in the case of symmetric demand information, from $Q_{R}^{\mathrm{SC}}>Q_{R}^{W}$, it can be seen that under the wholesale price contract, the retailer's optimal order quantity is smaller than the supply chain's optimal order quantity. Therefore, we can conclude that the wholesale price contract cannot optimize the profits of this three-level supply chain and cannot coordinate the entire supply chain. Under certain conditions, both the ZRS contract and the two-part tariff contract can increase the retailer's optimal order volume, thereby increasing the profit of the supply chain and achieving the purpose of coordinating the supply chain. With the two-part tariff contract, in order to maximize the profit of the entire supply chain, the manufacturer needs to set the wholesale price equal to the production cost, i.e., $W_{R}^{T}=C_{M}$. Currently, the retailer's optimal order quantity is the same as the supply chain's optimal order quantity, i.e., $Q_{R}^{T}=Q_{R}^{\mathrm{SC}}$. In the ZRS contract, when the manufacturer's revenue sharing ratio $\alpha$ satisfies the equation

$$
p-C_{M}-\frac{(1-\alpha) p(p+h)}{(1-\alpha) p+h}-\frac{k C_{S}^{\prime}}{Q_{S}} T\left(\frac{k F^{-1}\left(\frac{(1-\alpha) p}{(1-\alpha) p+h}\right)}{Q_{S}}\right)=0
$$

the retailer's optimal order quantity is the same as the supply chain's optimal order quantity, i.e., $Q_{R}^{Z}=Q_{R}^{\mathrm{SC}}$. In other words, these two types of contracts can maximize the profits of the supply chain and coordinate the entire supply chain.

\subsubsection{Demand information asymmetry}

We previously assumed that the demand information of manufacturers and retailers is symmetrical, but in real life, the demand information of manufacturers and retailers may also be asymmetrical. Because retailers are closer to consumers, they have more accurate demand information than manufacturers. Therefore, in this part, we assume that the retailer can predict demand information. The market demand information predicted by the retailer is represented by $u+\varepsilon, u$ obeys random distribution $F(\cdot), \varepsilon$ obeys random distribution $G(\cdot)$ probability density function is $g(\cdot), \varepsilon$ represents the error of the retailer's forecast of demand information. The value ranges of $u$ and $\varepsilon$ are $[\underline{u}, \bar{u}]$ and $[\underline{\varepsilon}, \bar{\varepsilon}]$, respectively. To avoid negative demand, we assume $\underline{u}+\underline{\varepsilon} \geq 0 . u^{*}$ is the expected value of demand information $u$. The demand forecast information $u$ is the only asymmetric information. The demand obtained by the retailer is the sum of the determined demand $u$ and $\varepsilon$ subject to a random distribution $G(\cdot)$, and the demand obtained by the supplier is the sum of two random variables $u$ and $\varepsilon$ subject to $F(\cdot)$ and $G(\cdot)$ respectively. The remaining variables are the same as when the information is symmetrical. 


\section{(i) Wholesale price contract}

We assume that the wholesale price is endogenous. The supplier determines the wholesale price based on the demand forecast information provided by the retailer. The game sequence between the manufacturer and the retailer under the wholesale price contract is as follows: (1) The retailer obtains demand forecast information and announces to the manufacturer that its forecast information is $\hat{u}$ but $\hat{u}$ may be different from the real forecast information $u$. (2) The supplier determines the wholesale price based on the retailer's forecast information, and the price meets the condition $C_{M}<W_{M}<p$. (3) The retailer determines the order quantity $Q_{R}$ based on the real demand information and the wholesale price. (4) Manufacturers manufacture products at unit production cost $C_{M}$. (5) During the sales season, when actual demand occurs, the retailer sells at the retail price $p$. And when there is a product surplus, it needs to be processed at the unit management cost $h$.

We use reverse induction to determine the sub-game perfect Nash equilibrium. After observing the wholesale price $W_{M}$, the retailer determines the order volume based on the real demand information predicted by it. For a given $W_{M}$, the retailer's optimal expected profit is:

$$
\Pi_{R}^{W}=p E_{x} \min \left(Q_{R}, u+\varepsilon\right)-h E_{x} \max \left(Q_{R}-u-\varepsilon, 0\right)-W_{M} Q_{R} .
$$

By deriving the profit function, we can get the retailer's optimal order quantity as:

$$
Q_{R}^{W}=G^{-1}\left(\frac{p-W_{M}}{p+h}\right)+u
$$

It can be clearly obtained from the above equation that the optimal order quantity decreases as the wholesale price $W_{M}$ increases, and decreases as the management cost $h$ increases.

Lemma 4.4. Using wholesale price contracts under asymmetric information, the retailer's expected profit will decrease as the wholesale price $W_{M}$ increases.

The retailer's expected profit depends on the wholesale price $W_{M}$ and the order quantity $Q_{R}$. When $W_{1}<W_{2}$, it's easy to check that

$$
\Pi_{R}^{W}\left(W_{1}, p\left(W_{1}\right)\right) \geq \Pi_{R}^{W}\left(W_{1}, p\left(W_{2}\right)\right) \geq \Pi_{R}^{W}\left(W_{2}, p\left(W_{2}\right)\right) .
$$

Therefore, the expected profit of the retailer decreases as the wholesale price increases. According to the retailer's optimal order quantity $Q_{R}^{W}$, the manufacturer's optimal wholesale price can be obtained as:

$$
W\left(Q_{R}^{W}\right)=p-(p+h) G\left(Q_{R}^{W}-u\right) .
$$

The manufacturer's expected profit function is:

$$
\Pi_{M}^{W}=\left(W_{M}-C_{M}\right) Q_{R}-W_{S} Q_{M}=\left(W_{M}-C_{M}\right)\left(G^{-1}\left(\frac{p-w_{M}}{p+h}\right)+u\right)-W_{S} Q_{M}
$$

However, the real forecast information $u$ is not transparent to the supplier, so his expected profit is actually:

$$
\Pi_{M}^{W}=E_{u}\left(W_{M}-C_{M}\right) Q_{R}-W_{S} Q_{M}=\left(W_{M}-C_{M}\right)\left(G^{-1}\left(\frac{p-W_{M}}{p+h}\right)+u^{*}\right)-W_{S} Q_{M} .
$$

There's an inverse of distribution function and it's not convenient to calculate the best wholesale price directly, so we let $y=G^{-1}\left(\frac{p-w_{M}}{p+h}\right)+u^{*}$. The wholesale price be expressed as a function of $y$ : $W_{M}=p-(p+h) G\left(y-u^{*}\right)$ and the expected the supplier is profit of the supplier is: $\Pi_{M}^{W}=\left[p-(p+h) G\left(y-u^{*}\right)-C_{M}\right] y-W_{S} Q_{M}$. The optimal decision problem for supplier is $y_{0}=\arg \max _{y \geq 0} \Pi_{M}^{W}(y)$. 
Lemma 4.5. If the distribution function $G(\varepsilon)$ has IFR property (i.e., $\frac{g(\varepsilon)}{G(\varepsilon)}$ weakly increases with for all $\varepsilon$ such that $G(\varepsilon)<1)$, there's a unique $y_{0}$ maximizing $\Pi_{M}^{W}(y)$ and it is determined by the following equation:

$$
\frac{h+C_{M}+W_{S} k}{p+h}=\bar{G}\left(y-u^{*}\right)\left(1-\frac{g\left(y-u^{*}\right) y}{\bar{G}\left(y-u^{*}\right)}\right) .
$$

If the equation has no solution in $\left(u^{*}+\underline{\varepsilon}, u^{*}+\bar{\varepsilon}\right)$, the optimal decision problem for supplier $y^{0}=u^{*}+\underline{\varepsilon}$.

Theorem 4.6. Under wholesale price contracts, the supplier always ignores the provided forecast information and sets wholesale price $W_{M}^{0}=p-(p+h) G\left(y^{0}-u^{*}\right)$.

If the manufacturer believes in the demand information provided by the retailer, then the manufacturer's expected profit is $\Pi_{M}^{W}=\left(W_{M}-C_{M}\right)\left(G^{-1}\left(\frac{p-W_{M}}{p+h}\right)+u\right)-W_{S} Q_{M}$. The profit function represented by the retailer's order quantity $Q_{R}$ is $\left[p-(p+h) G\left(Q_{R}-u\right)-C_{M}\right] Q_{R}-W_{S} k Q_{R}$, taking the derivative of $Q_{R}$ in the profit function, we can get:

$$
\frac{h+C_{M}+W_{S} k}{p+h}=\bar{G}\left(Q_{R}-u\right)\left(1-\frac{g\left(Q_{R}-u\right) Q_{R}}{\bar{G}\left(Q_{R}-u\right)}\right)
$$

From the above equation, it is easy to prove that $Q_{R}$ increases as $u$ increases. From the retailer's expected profit function, the retailer's expected profit increases as the order quantity $Q_{R}$ increases and increases as the wholesale price $W_{M}$ decreases. That is, the expected profit of the retailer increases as the demand information $u$ increases. Therefore, retailers have an incentive to provide manufacturers with a higher level of demand than real demand information, so that manufacturers set a lower wholesale price $W_{M}$ to increase their profits. However, the supplier cannot distinguish the authenticity of the demand information provided by the retailer. The manufacturer's best choice is to ignore the demand information provided by the retailer and set the wholesale price according to the expected value $u^{*}$ of the demand information. Therefore, in the wholesale price contract, effective information sharing does not exist.

In the case of asymmetric demand information, when the three-level supply chain makes centralized decisionmaking, the expected profit of this supply chain can be expressed as:

$$
E\left(\Pi_{\mathrm{SC}}\right)=p E_{\varepsilon} \min \left(Q_{R}, u+\varepsilon\right)-h E_{\varepsilon} \max \left(Q_{R}-u-\varepsilon, 0\right)-C_{M} Q_{R}-C_{S} Q_{S}-C_{S}^{\prime} E\left(Q_{M}-Z Q_{S}\right)^{+} .
$$

This function expression is a concave function, and there is a unique $Q_{R}$ to maximize the expected profit of the supply chain. Find the first derivative of the above expression:

$$
p-C_{M}-(p+h) G\left(Q_{R}^{\mathrm{SC}}-u\right)-\frac{k C_{S}^{\prime}}{Q_{S}} T\left(\frac{k Q_{R}^{\mathrm{SC}}}{Q_{S}}\right)=0 .
$$

Theorem 4.7. It can be seen from the above that $W_{M}>C_{M}+\frac{k C_{S}^{\prime}}{Q_{S}} T\left(\frac{k Q_{R}^{\mathrm{SC}}}{Q_{S}}\right)$, the optimal order quantity of this three-level supply chain $Q_{R}^{\mathrm{SC}}$ is greater than the optimal order quantity of the retailer $Q_{R}^{W}$. In other words, the wholesale price contract cannot maximize the profits of this three-level supply chain and cannot coordinate the supply chain.

Comparing (4.7) and (4.8), we get the retailer's order quantity under the wholesale price contract is less than the optimal order quantity in the supply chain. Therefore, the wholesale price contract cannot coordinate the supply chain. In general, the wholesale price contract can neither achieve effective information sharing nor coordinate the supply chain. The inefficiency caused by wholesale price contracts mainly comes from information asymmetry and double marginal effects. Next, we study whether the two pricing contracts and the ZRS contract can solve the problem of low efficiency and achieve the purpose of coordinating the supply chain. 


\section{(ii) Coordination contract}

Under information asymmetry, when the manufacturer provides two-part tariff contract to the retailer, the game sequence between the manufacturer and the retailer is as follows: (1) The retailer predicts demand information and announces to the manufacturer that its forecast information is $\hat{u}$. (2) The supplier determines the wholesale price and fixed fee $F$ according to the retailer's forecast information, and the wholesale price satisfies $C_{M}<W_{M}^{T}<p$. (3) The retailer determines the order quantity $Q_{R}$ based on the demand forecast information $u$ and the wholesale price $W_{M}^{T}$. (4) Manufacturers manufacture products at unit cost $C_{M}$. (5) During the sales season, the retailer sells at the retail price $p$, and the unsold products need to be managed at a unit cost $h$.

We use reverse induction to determine the sub-game perfect Nash equilibrium. After knowing the wholesale price $W_{M}^{T}$, the retailer determines the order quantity based on the real demand information predicted by it. For a given $W_{M}^{T}$, the retailer's optimal expected profit is:

$$
\Pi_{R}^{T}=p E_{\varepsilon} \min \left(Q_{R}, u+\varepsilon\right)-h E_{\varepsilon} \max \left(Q_{R}-u-\varepsilon, 0\right)-W_{M}^{T} Q_{R}-F .
$$

This function expression is a concave function, and there is a unique $Q_{R}$ to maximize the expected profit of the retailer. Find the first derivative of the above expression:

$$
Q_{R}^{T}=G^{-1}\left(\frac{p-W_{M}^{T}}{p+h}\right)+u .
$$

When manufacturers and retailers choose the ZRS contract, the contract contains a fixed fee $F$, if the retailer provides excessive demand information, it will need to pay a higher fixed fee, so the retailer will not provide false demand information. The game sequence between the manufacturer and the retailer is as follows: (1) The retailer predicts demand information and announces to the manufacturer that its forecast information is $\hat{u}$. (2) The supplier determines the revenue sharing ratio $\alpha$ based on the retailer's forecast information and fixed fee $F$. (3) The retailer determines the order quantity $Q_{R}$ based on the demand forecast information $u$ and the sharing ratio $\alpha$. (4) Manufacturers manufacture products at unit cost $C_{M}$. (5) During the sales season, the retailer sells at the retail price $p$, and the unsold products need to be managed at a unit cost $h$.

We use reverse induction to determine the sub-game perfect Nash equilibrium. After knowing the revenue sharing ratio $\alpha$, the retailer determines the order quantity based on the real demand information predicted by itself. For a given revenue sharing ratio $\alpha$, the retailer's optimal expected profit is:

$$
\Pi_{R}^{Z}=(1-\alpha) p E_{\varepsilon} \min \left(Q_{R}, u+\varepsilon\right)-h E_{\varepsilon} \max \left(Q_{R}-u-\varepsilon, 0\right)-S .
$$

This function expression is a concave function, and there is a unique $Q_{R}$ to maximize the expected profit of the retailer. Find the first derivative of the above expression: $Q_{R}^{Z}=G^{-1}\left(\frac{(1-\alpha) p}{(1-\alpha) p+h}\right)+u$.

Lemma 4.8. In the two-part tariff contract, the retailer's optimal order quantity is inversely proportional to the wholesale prices. In the ZRS contracts, the retailer's optimal order quantity is inversely proportional to the revenue sharing ratio. And the optimal order quantity of the retailer under the two contracts both increases with the increase of the demand information $u$.

It can be seen from Theorem 4.7 that the optimal order quantity under the wholesale price contract is smaller than the optimal order quantity of the supply chain. With the two-part tariff contract, the manufacturer's lower wholesale price can encourage retailers to increase the number of orders. Therefore, an increase in the number of orders within a certain range can not only increase the profit of the retailer, but also increase the profit of the manufacturer. Manufacturers set a lower wholesale price as far as possible within the range of no loss, which can make both manufacturers and retailers profitable. For the ZRS contract, the manufacturer setting a zero wholesale price and a certain revenue sharing ratio $\alpha$ can reduce the risk of the retailer's uncertainty about market demand, and better encourage the retailer to increase the number of orders, which greatly increased the 
profits of both parties. In addition, the increase in demand information $u$ can increase the retailer's optimal order quantity, thereby increasing supply chain profits. Therefore, retailers should take corresponding measures to increase consumer demand.

Theorem 4.9. According to the retailer's optimal order quantity $Q_{R}^{*}(* \in(W, Z, T))$, it can be known that when $W_{M}^{T}<W_{M}$, we can get $Q_{R}^{T}>Q_{R}^{W}$. When $p$ and $h$ are constant, then $\alpha<1-\frac{h\left(p-W_{M}\right)}{p\left(h+W_{M}\right)}$, we can get $Q_{R}^{Z}>Q_{R}^{W}$.

The above theorem shows that the two-part tariff contract and the ZRS contract can increase the number of retailers' orders under certain conditions. Combining with Theorem 4.7, these two contracts can increase the profit of the supply chain and achieve the effect of coordinating the supply chain. When the manufacturer chooses two-part tariff contract, its wholesale price should be less than the wholesale price in the wholesale price contract, which can encourage retailers to increase the number of orders and obtain more profits. When the manufacturer chooses the ZRS contract, it needs to set the revenue sharing ratio $\alpha$ to satisfy the condition: $\alpha<1-\frac{h\left(p-W_{M}\right)}{p\left(h+W_{M}\right)}$. At this time, the retailer's optimal order quantity can be greater than the optimal order quantity of the wholesale contract, and the profit of the retailer and the supply chain can be increased.

It can be seen from the above that the profit function of this supply chain is a concave function, and there is a unique optimal order quantity that maximizes the profit. In the two-part tariff contract, in order to maximize the profit of the supply chain, the manufacturer needs to set the wholesale price equal to the production cost, that is $W_{R}^{T}=C_{M}$. At this time, the optimal order quantity of the retailer is the same as the optimal order quantity of the supply chain, i.e., $Q_{R}^{T}=Q_{R}^{\mathrm{SC}}$. In the ZRS contract, when the manufacturer's revenue sharing ratio $\alpha$ satisfies the following equation:

$$
p-C_{M}-\frac{(1-\alpha) p(p+h)}{(1-\alpha) p+h}-\frac{k C_{S}^{\prime}}{Q_{S}} T\left(\frac{k F^{-1}\left(\frac{(1-\alpha) p}{(1-\alpha) p+h}+u\right)}{Q_{S}}\right)=0 .
$$

The optimal order quantity of the retailer is the same as the optimal order quantity of the supply chain, i.e., $Q_{R}^{Z}=Q_{R}^{\mathrm{SC}}$. In other words, these two types of contracts can maximize the profit of the supply chain and coordinate the entire supply chain.

In summary, the two-part tariff contract and the ZRS contract can both eliminate the double marginal effect, increase the interests of both parties to the contract, and coordinate the entire supply chain. But there are certain differences between these two contracts. In the two-part tariff contract, the retailer pays a unit wholesale price and a fixed fee to order the product before the product is sold. In the ZRS contract, after the product is sold, the retailer shares the revenue with the manufacturer's revenue ratio $\alpha$ and additional expense. For the remaining products, the retailer under the ZRS contract does not need to pay any fees to the supplier.

\subsubsection{Risk sharing}

Many scholars have studied the use of repurchase, quantity discount, revenue sharing, profit sharing and full return contracts in the supply chain to reduce the risk of retailers and coordinate the supply chain under uncertain demand. Among them, the revenue sharing contract has been widely studied. The revenue-sharing contract is that the manufacturer provides the retailer with a lower wholesale price. After the retailer completes the sale, the retailer will share the revenue with the manufacturer in a fixed proportion. The two-part tariff contract are consistent with the wholesale price contracts, requiring retailers to purchase products from manufacturers at unit wholesale prices. This paper studies whether in a three-level supply chain, when the demand is uncertain, whether the adoption of the ZRS contract including the revenue-sharing contract and the two-part tariff contract can reduce the retailer's risk and coordinate the supply chain.

The ZRS contract adopted in this article is that the manufacturer does not charge the retailer the wholesale price, but replaces it with a fixed fee $S$. After the retailer's sales period is completed, the retailer then shares the revenue with the manufacturer in a proportion $\alpha$. The ZRS contract and the revenue-sharing contract have the same mechanism for reducing retailer risk. They charge lower fees first, and then ask the retailer to share part 
of the revenue after the retailer completes the sale. When the demand information is symmetrical, the optimal order quantities of the retailer and the supply chain under the ZRS contract are: $Q_{R}^{Z}=F^{-1}\left(\frac{(1-\alpha) p}{(1-\alpha) p+h}\right)$

$$
p-C_{M}-(p+h) F\left(Q_{R}^{\mathrm{SC}}\right)-\frac{k C_{S}^{\prime}}{Q_{S}} T\left(\frac{k Q_{R}^{\mathrm{SC}}}{Q_{S}}\right)=0 .
$$

In the ZRS contract, to achieve coordination in the supply chain, manufacturers need to set the revenue sharing ratio $\alpha$ to satisfy the following equation:

$$
p-C_{M}-\frac{(1-\alpha) p(p+h)}{(1-\alpha) p+h}-\frac{k C_{S}^{\prime}}{Q_{S}} T\left(\frac{k F^{-1}\left(\frac{(1-\alpha) p}{(1-\alpha) p+h}+u\right)}{Q_{S}}\right)=0 .
$$

In addition, the fixed fee $S$ in the ZRS contract also requires the manufacturer to set within a certain range, within which the profits of both the retailer and the manufacturer must be greater than the profits under the wholesale price contract. In this way, both manufacturers and retailers are willing to adopt the contract. Therefore, when the optimal order quantity of the retailer under the ZRS contract is equal to the optimal order quantity of the supply chain, the value range of the fixed fee $S$ should be:

$$
\pi_{M}^{Z}-\pi_{M}^{W}<S<\pi_{R}^{Z}-\pi_{R}^{W}
$$

In general, the use of two-part tariff contract in this three-tier supply chain can only achieve the function of coordinating the supply chain and cannot effectively reduce the risk of retailers. The ZRS contract can not only coordinate the supply chain, but also enable manufacturers to help small-scale retailers bear the risks caused by uncertain demand and encourage retailers to increase their orders. The increase in orders will make retailers work harder to sell. More profits and increased sales will increase consumer demand, which will ultimately have a positive effect on the entire supply chain. Therefore, when the revenue sharing ratio $\alpha$ and the fixed cost $S$ meet certain conditions, it is more advantageous to adopt the ZRS contract than to adopt two-part tariff contract.

\subsection{Yield uncertainty}

In daily life, uncertain yield is also a relatively common situation. For example, high-tech products often have insufficient yield due to technical failures and other reasons. In addition, when producing agricultural products, there may be insufficient or excessive yield due to weather and production technology. Uncertain yield will also bring greater risks to suppliers and the supply chain. Next, in the manufacturer-led supply chain, when the yield is random, how the manufacturer can design a contract to reduce the risk of the supplier, increase the enthusiasm for production, and help the supplier get more profits.

\subsubsection{Wholesale price contract}

We previously assumed that in this three-level supply chain, a wholesale price contract is used between the supplier and the manufacturer. However, due to the uncertainty of yield, suppliers of raw materials may have two situations, insufficient or excess yield. When the supplier's yield is insufficient, in order to fulfill the manufacturer's order quantity, it needs to purchase raw materials at higher prices from other markets, the unit cost is $C_{S}^{\prime}$. For over-production, the excess cotton after matching the manufacturer's demand is stored at a holding cost. the supplier need to consume a certain cost to store these materials. In short, when the yield is insufficient or the yield is too high, it is not good for the supplier. We assume that the supplier is small in scale and weak in taking risks. If the supplier loses its long-term interests, it may happen that the supplier provides the manufacturer with lower quality raw materials or fails to complete the contract. These situations are also detrimental to the manufacturer. So, we study if manufacturers provide risk-sharing contract to help suppliers bear part of the risks, whether it will increase supplier profits and coordinate the supply chain. 
When the manufacturer does not share the risk, the expected profits of the supplier and the supply chain SC are:

$$
\begin{aligned}
E\left(\Pi_{S}\right) & =W_{S} Q_{M}-C_{S} Q_{S}-C_{S}^{\prime} E\left(Q_{M}-Z Q_{S}\right)^{+} \\
E\left(\Pi_{S C}\right) & =p E \min \left(Q_{R}, X\right)-h E \max \left(Q_{R}-X, 0\right)-C_{M} Q_{R}-C_{S} Q_{S}-C_{S}^{\prime} E\left(Q_{M}-Z Q_{S}\right)^{+}
\end{aligned}
$$

Derivation of the above two profit functions shows that their optimal planned yield $Q_{S}$ values are equal, both are:

$$
\begin{aligned}
Q_{S}^{*} & =Q_{M} /\left[\Theta^{-1}\left(\frac{C_{S}}{C_{S}^{\prime}}\right)\right] \\
\Theta(x) & =\int_{0}^{x} z t(z) \mathrm{d} z .
\end{aligned}
$$

\subsubsection{Design of risk-sharing contract}

In this subsection, we demonstrate the application of the risk-sharing contract to improve the profitability of the supplier. The supplier high financial losses due to production uncertainty. To address these issues, we propose a special risk-sharing contract (RS) between the supplier and the manufacturer to handle both the over-production and under-production risks of the supplier. The mechanism is described below:

First, the manufacturer offers a contract in which it shares the production risk of the supplier. In case of over-production, the manufacturer purchases the excess production, at a payback price $b$. In the case of underproduction, the manufacturer shares a fraction $\beta$, where $\beta \in[0,1]$, of the supplier's spot market procurement cost. In return, the supplier supplies production to the manufacturer at a reduced price $W_{S}^{\prime}$. To proceed with our analysis, we must assume: $b<W_{S}^{\prime}, C_{S}^{\prime}>C_{S}$.

Under the risk-sharing contract, the supplier's expected profit function is concave to the planned yield $Q_{S}$. There is an optimal $Q_{S}^{*}$ that maximizes the supplier's expected profit value. The optimal planned yield $Q_{S}^{*}$ is as follows:

$$
\begin{aligned}
& Q_{S}^{\mathrm{RS}}=Q_{M} /\left[\Theta^{-1}\left(\frac{C_{S}-b \mu}{(1-\beta) C_{S}^{\prime}-b}\right)\right] \\
& \Theta(x)=\int_{0}^{x} z t(z) \mathrm{d} z .
\end{aligned}
$$

When the manufacturer shares risks, the overall profit of the supply chain will not change, and the optimal planned yield of the supply chain is still shown in equation (4.11). Therefore, when adopting the risk-sharing contract, in order to keep the maximum profit of the supply chain unchanged, the supplier should make the optimal planned yield under the RS contract equal to the optimal planned yield of the supply chain. That is, when $b$ and $\beta$ satisfy the following equation, the supply chain achieves coordination:

$$
b=\frac{\beta C_{S} C_{S}^{\prime}}{\mu C_{S}^{\prime}-C_{S}}
$$

In general, when the supplier's production is uncertain, the manufacturer's adoption of the risk-sharing contract can help the supplier reduce certain risks and coordinate the supply chain. When the supplier's yield is too high, the manufacturer will recycle the excess products at a lower wholesale price, which can help the supplier increase a certain amount of profit. When the yield is too low and the supplier buys from other markets at a high cost, the manufacturer subsidizes it to reduce the loss of supplier profits.

\section{NUMERICAL ANALYSIS}

In this part, we use MATLAB to perform numerical analysis to demonstrate the profitability of supply chain members under different contracts, the impact of order quantity on retailers, the impact of yield and demand 
TABLE 3. Value of each parameter.

\begin{tabular}{lllllllllllll}
\hline \hline$p$ & $W_{M}$ & $W_{M}^{T}$ & $\alpha$ & $h$ & $C_{M}$ & $W_{S}$ & $C_{S}$ & $C_{S}^{\prime}$ & $W_{S}^{\prime}$ & $b$ & $\beta$ & $\mu$ \\
\hline 10 & 6 & 3 & 0.6 & 0.2 & 2 & 0.2 & 0.02 & 0.1 & 0.185 & 0.027 & 0.4 & 0.5 \\
\hline
\end{tabular}
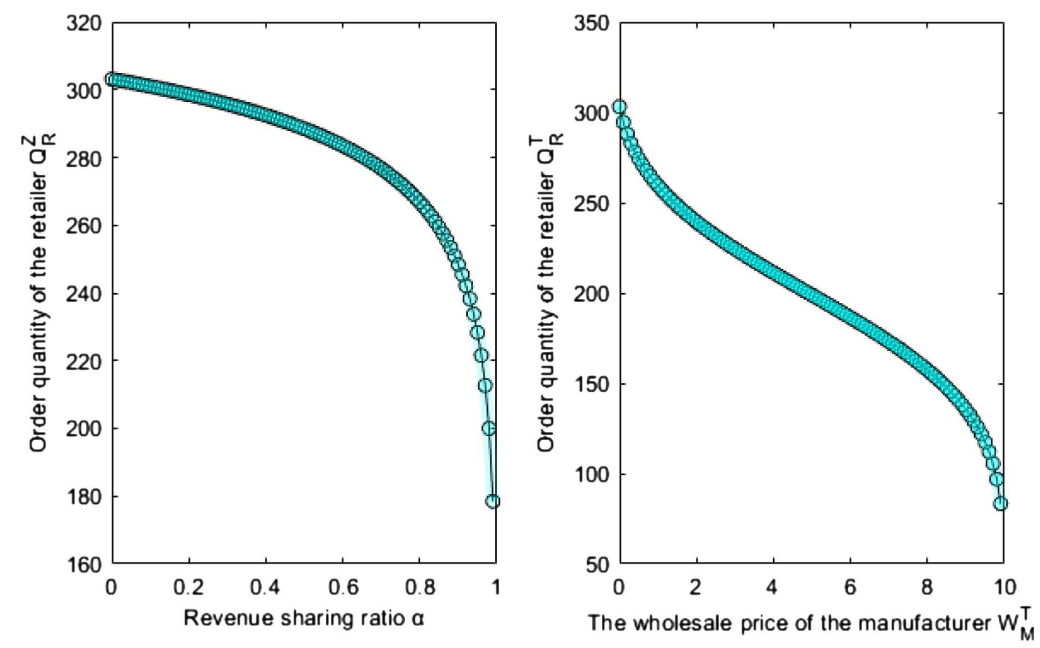

FIgURE 1. The influence of $\alpha$ in the ZRS contract and $W_{M}^{T}$ in the two-part tariff contract on the retailer's optimal order quantity $Q_{R}$.

uncertainty on supply chain coordination, and the impact of the risk sharing mechanism on each supply chain members' profitability. We assume that product demand $(X)$ is normally distributed, with a mean value of 200 units and a standard deviation of 50 units. Manufacturers and retailers have symmetrical demand information. In addition, the random yield $Z$ of the supplier's raw materials is uniformly distributed on $[0,1]$. The data used in our numerical analysis is similar to the data in the following papers, such as Adhikari and Bisi [1]. Table 3 is the numerical hypothesis of each parameter in the model.

Figure 1 shows the impact of the manufacturer's revenue sharing ratio $\alpha$ to the retailer in the ZRS contract and the manufacturer's wholesale price $W_{M}^{T}$ in the two-part tariff contract on the retailer's optimal order quantity $Q_{R}$. For the ZRS contract, as the revenue sharing ratio $\alpha$ increases, the retailer's optimal order quantity $Q_{R}$ gradually decreases, and the rate of decrease increases as the revenue sharing ratio $\alpha$ increases. For the two-part tariff contract, the retailer's optimal order quantity $Q_{R}$ also decreases with the increase of the wholesale price $W_{M}^{T}$, and the rate of decrease is first increased, then decreased, and then increased. It can be seen intuitively from the figure that a small revenue sharing ratio has no obvious effect on the retailer's optimal order quantity. When the revenue sharing ratio is large, for example, greater than 0.8, the retailer's optimal order quantity drops sharply. In contrast, the wholesale price $W_{M}^{T}$ in the two-part tariff contract has a significant impact on the retailer's optimal order quantity. When the wholesale price is 2, the order quantity has dropped below 120. Therefore, manufacturers can set a higher revenue sharing ratio in the ZRS contract to obtain profits.

Figure 2 describes the impact of retailer's order quantity $Q_{R}$ on the SC profit. No matter what contract the supply chain adopts, its profit function always increases first and then decreases as the retailer's order quantity $Q_{R}$ increases. When the order quantity is 230 , the profit of this supply chain reaches the maximum value of 1416. In other words, in order to coordinate the supply chain and maximize the profit of the entire supply chain, the manufacturer should adopt a coordination contract to make the retailer's optimal order quantity 230 . At 


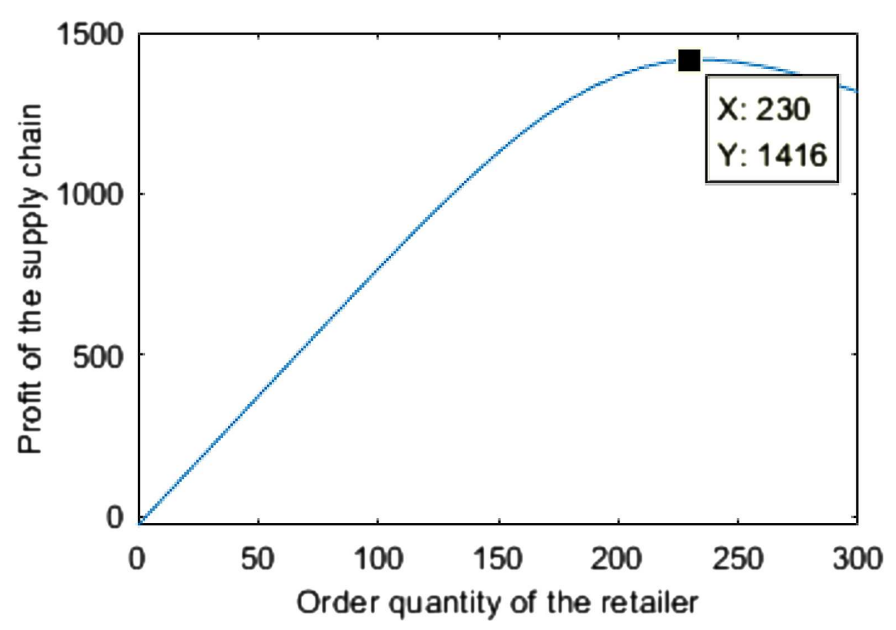

FiguRE 2. The impact of retailer's order quantity $Q_{R}$ on profit of the supply chain.

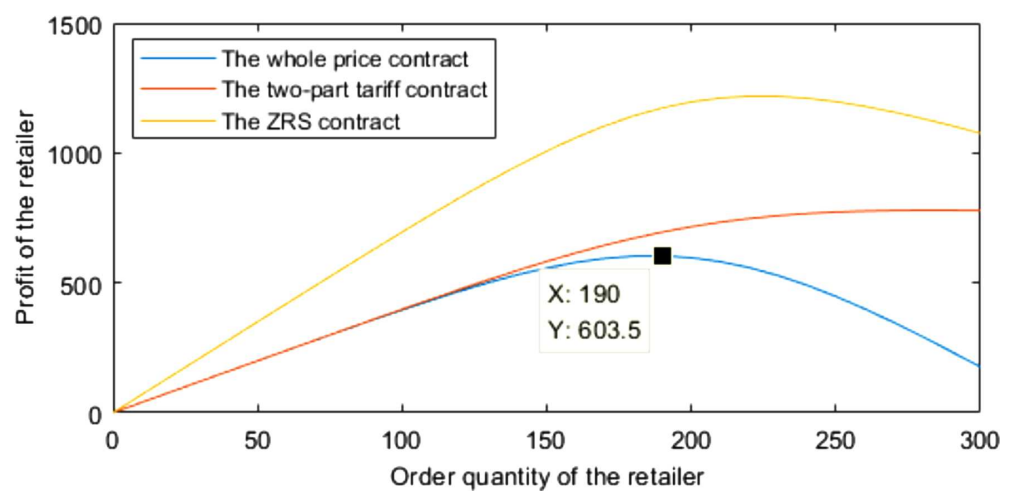

FiguRE 3 . The impact of retailer's order quantity $Q_{R}$ on retailer's profit in three contracts.

this time, the manufacturer should distribute the excess profits through fixed expenses, so that both the retailer and itself are profitable.

Figure 3 reflects the impact of retailer's order quantity $Q_{R}$ on retailer's profit under the three contracts. For the wholesale price contract $(W)$, its optimal order quantity is 190 , and it can be seen from Figure 2 that the optimal order quantity of the supply chain is 230 . Therefore, the wholesale price contract cannot maximize the profit of the supply chain and cannot coordinate the supply chain. From Theorems 4.3, 4.7 and 4.9, we can see that under information symmetry and information asymmetry, both the ZRS contract $(Z)$ and the two-part tariff contract $(T)$ can increase the retailer's optimal order quantity. And when each parameter satisfies certain conditions, the optimal order quantity under these two contracts can be equal to the optimal order quantity of the supply chain. For the ZRS contract $(Z)$, when the retailer's order quantity is small, the extra cost $S$ can be set to zero, so that the retailer's profit is not less than the profit under the wholesale price contract. When the retailer has a large order quantity, the retailer is more profitable than the wholesale contract. At this time, the manufacturer can set a reasonable additional fee $S$ so that both parties can benefit. For two-part tariff contract $(T)$, since the retailer's optimal order quantity is consistent with the supply chain's optimal order quantity, a rational retailer will choose this optimal order quantity. That is, the use of this contract can maximize the profit of the supply chain. For the fixed cost $F$ in the contract, the manufacturer should set a reasonable value 


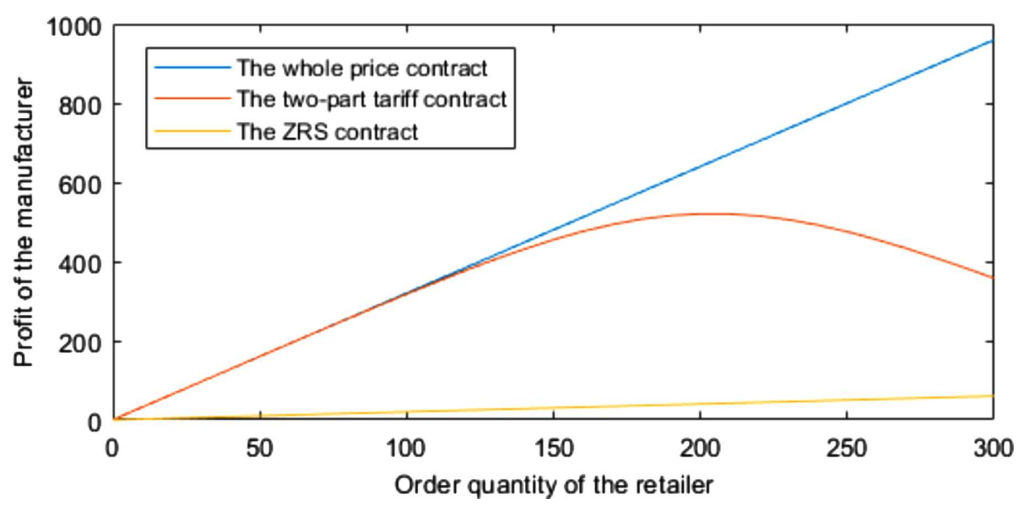

FiguRE 4. The impact of retailer's order quantity $Q_{R}$ on manufacturer's profit in three contracts.

so that the profits of both parties are increased compared with the wholesale contract. In addition, it can be clearly seen from the figure that the profits of the ZRS contract and the two-part tariff contract did not drop as significantly as the wholesale contract when the order quantity was large. This shows that these two contracts can enable manufacturers to share the risks of retailers.

Figure 4 reflects the impact of retailer's order quantity $Q_{R}$ on the manufacturer's profit under the three contracts. The profit of the manufacturer under the wholesale contract increases as the order quantity increases. Under the ZRS contract, the manufacturer's optimal order quantity is 200. However, when the optimal order quantity of the supply chain is 230 , the profit brought to the supply chain is greater than when the order quantity is 200 , so a rational retailer will choose the optimal order quantity of the supply chain. At this time, the manufacturer needs to set a reasonable additional fee $S$, so that both the manufacturer and the retailer can increase their profits under the contract compared to the wholesale contract. In other words, under this contract, both the manufacturer and the retailer are willing to execute, so that supply chain coordination can be achieved. It is obvious from the figure that under the two-part tariff contract, when the fixed fee $F$ is not considered, the manufacturer's profit is very small. Therefore, manufacturers should set larger fixed costs to maximize their profits when retailers are profitable.

In general, the wholesale price contract cannot maximize the profit of the supply chain, and cannot allow manufacturers to share the risk of uncertain demand faced by retailers. However, as can be seen from the above figures, the use of the ZRS contract or the two-part tariff contract can eliminate the double marginal utility, maximize the profit of the supply chain, and achieve the effect of coordinating the supply chain. Moreover, these two contracts can play a role in risk-sharing, enabling manufacturers to help retailers bear certain risks, and encourage retailers to increase the number of orders. These two contracts may also make retailers work harder to sell, thereby achieving a positive effect of increasing demand.

It can be seen from Figure 5 that the profit of the three-tier supply chain increases first and then decreases with the increase in the planned yield of the supplier. That is, there is an optimal planned yield that maximizes the profit of the supply chain. According to formula (4.11), the optimal planned yield of the supply chain is consistent with the optimal planned yield of the supplier. Moreover, regardless of whether the manufacturer provides a risk-sharing contract, the profit function of this supply chain will not change. Therefore, when adopting the risk-sharing contract, the supplier should reasonably set the normal supply wholesale price $W_{S}$ and the wholesale price $W_{S}^{\prime}$ when the yield is surplus to ensure that their optimal planned yield is consistent with the optimal planned yield of the supply chain.

It can be seen from Figure 6 that in both the wholesale price contract $(W)$ and the risk-sharing contract (RS), the supplier's profit always increases first and then decreases. And, in both cases, the supplier's optimal planned yield is the same. In addition, it can be clearly seen that after adopting the risk-sharing contract, the 


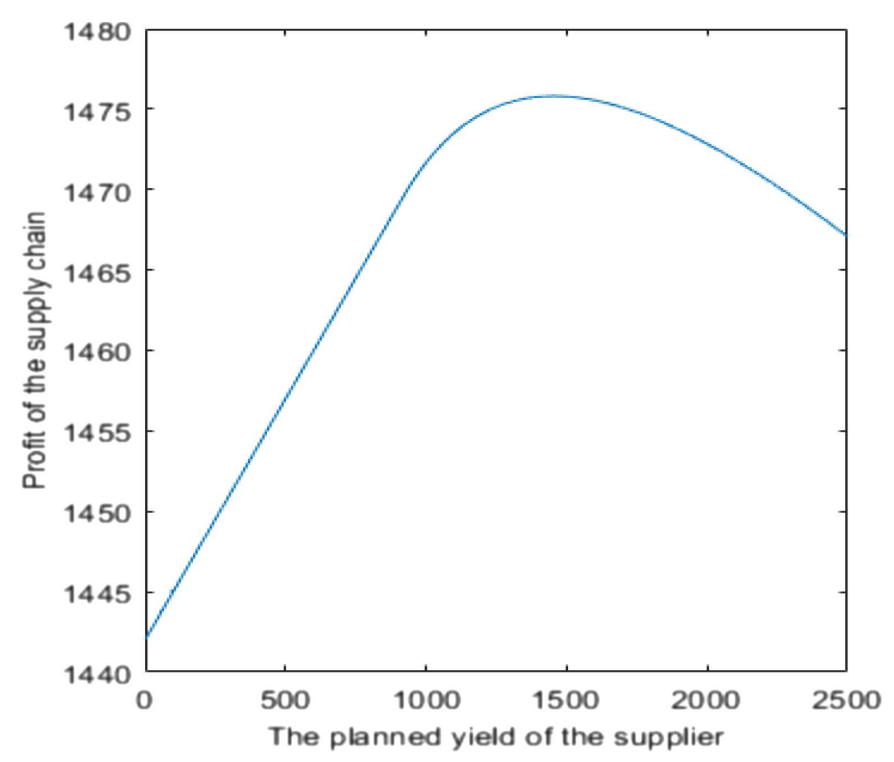

FIGURE 5. The impact of planned yield on supply chain profit.

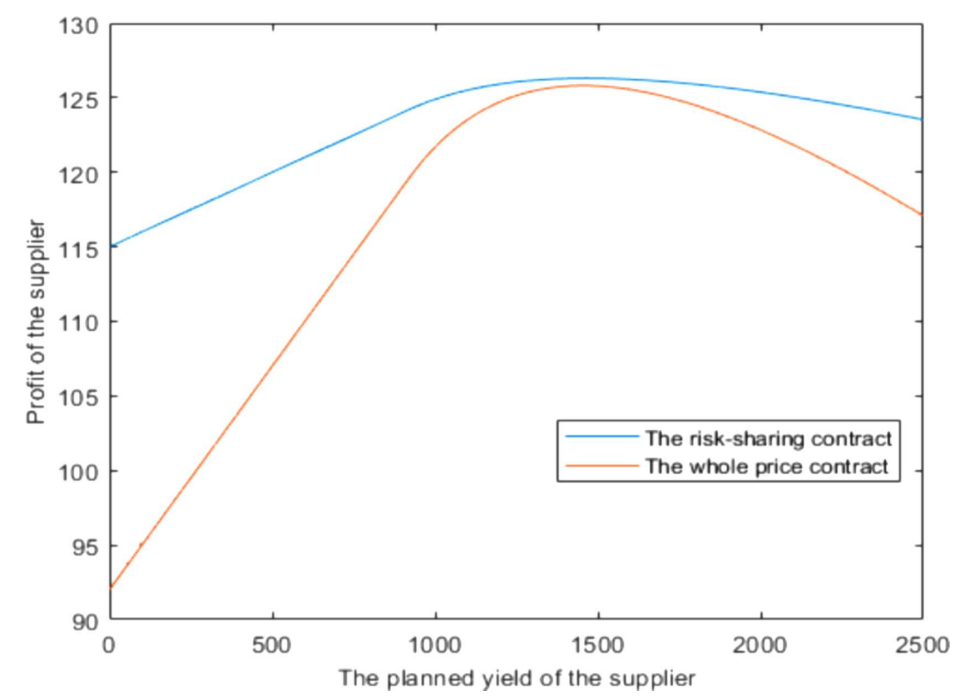

FiguRE 6 . The impact of planned yield on the supplier before and after risk sharing.

supplier's profit has increased significantly, and when the planned yield is relatively small or relatively large, the fluctuation of the supplier's profit under RS is relatively small. This phenomenon shows that the use of risk-sharing contract can help suppliers reduce risks and increase certain profits.

It can be seen from Figure 7 that with the increase in the production rate $Z$, the supplier's profit gradually increases. When the production rate is zero, the supplier can still benefit. At this time, the supplier can buy from other markets and then complete the manufacturer's order, but the supplier can obtain lower profits. When the supplier's production rate is low $(<0.4)$, it is more beneficial to the supplier to adopt a risk-sharing contract, because the risk-sharing allows the manufacturer to help the supplier take risks. When the yield is 


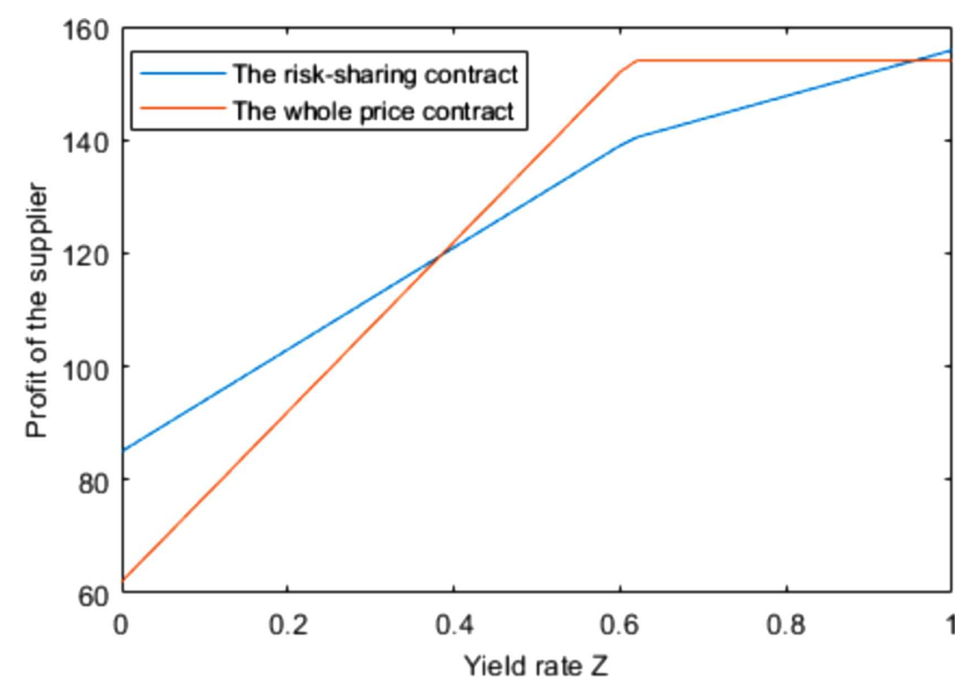

Figure 7 . The impact of random yield $Z$ on the supplier profits.

higher, the benefit of adopting a risk-sharing contract is lower. When the yield continues to increase close to 1 , the supplier under the RS benefit more. Therefore, when the supplier's production rate is low, you can choose to adopt a risk-sharing contract; and at this time, the supplier should strive to increase the production rate to increase their own profits.

\section{Conclusion}

In this paper, we study a three-tier supply chain consisting of a risk-neutral manufacturer and a risk-averse supplier and retailer for the production and supply of perishable products with short shelf life facing stochastic yield and market demand. We use probability distribution to express the uncertainty of yield and demand. For demand uncertainty, we study the impact of contracts on the supply chain under both information symmetry and information asymmetry. For yield uncertainty, we design a risk-sharing contract to share the risks faced by suppliers.

This study has made some noteworthy contributions to the existing literature on supply chain's coordination contracts of the perishable products with short shelf life. We consider the unique characteristics of these supply chain in the developed model (including stochastic yield, uncertain demand, the risk-averse decision maker, unbalanced risk, information asymmetry), and examine how these unique characteristics influence the optimal decisions and utilities of the supply chain, which making our problem setting uniquely different from the assumptions made in previous studies. In addition, we design a risk-sharing contract from the perspective of supply chain management to help suppliers share risks and achieve supply chain coordination in response to the uncertain yield risks faced by the supplier. Moreover, our analyses lead to several interesting findings and managerial implications in supply chain practices.

First, we find that when demand information is asymmetric, manufacturers always ignore the demand forecast information provided by retailers under the wholesale price contract. This result shows that effective information sharing cannot be achieved under the wholesale price contract. Hence, as the leader of the supply chain, manufacturers should adopt incentive measures or adopt ZRS contracts to enable retailers to share real demand information in order to coordinate the supply chain. In this way, manufacturers can make reasonable decisions and maximize the profits of the supply chain. 
Second, we find the ZRS contract and the two-part tariff contract can coordinate the supply chain to maximize the profit in the two situations of information symmetry and information asymmetry. Meanwhile, the ZRS contract allows the manufacturer to help the retailer sharing more risks. Therefore, manufacturers with a dominant position should encourage retailers to choose two-part tariff contracts or ZRS contracts, and obtain maximum profits by setting contract parameters reasonably (such as sharing ratio, wholesale price, etc.). Moreover, when the retailer is risk-neutral or the degree of risk aversion is low, the two-part tariff contract is optimal. When the retailer's degree of risk aversion is high, the ZRS contract is the best choice. These contracts we proposed not only solves the supply chain bullwhip effect to achieve the coordination of the supply chain, but can also share the risks of retailers.

Third, we find that when the manufacturer provides a risk-sharing contract to the supplier, the expected profit of the supply chain has not changed, but it can effectively reduce the supplier's risk. In practices, the manufacturer can borrow the thought of the risk-sharing contract to design tailored mechanism for the supply chain. The sharing of cost of buying at high prices from other markets help to incentive the supplier, while the buyback for the part that exceeds the order quantity can help avoid waste, which is equivalent to saving cost. By doing this, it can ensure that suppliers can deliver orders on time without affecting the production and sales of subsequent products.

This study has some limitations and thus presents extensions for future research. For instance, to simplify our model, we only consider one manufacturer, one supplier and one retailer. In real situations, however, the supply chain is usually a network consisting of one manufacturer and multiple suppliers and retailers or one retailer and multiple manufacturers. Hence, extending our work into these different structural scenarios would be interesting. Moreover, Subsequent research could relax certain assumptions made in these models. It is interesting to extend the analysis by including nonlinear cost (reflecting production economies of scale) or other pricing policies, such as quantity discount.

Acknowledgements. This work is supported by the Major Project Funds of Philosophy and Social Science Research of Jiangsu Universities (No.2021SJZDA134), the Humanities and Social Science Foundation of Ministry of Education (No.18YJA630088), and the Fundamental Research Funds for the Central Universities (No.JUSRP321016).

\section{REFERENCES}

[1] A. Adhikari, A. Bisi and B. Avittathur, Coordination mechanism, risk sharing, and risk aversion in a five-level textile supply chain under demand and supply uncertainty. Eur. J. Oper. Res. 282 (2019) 93-107.

[2] G.P. Cachon and A.G. Koek, Competing manufacturers in a retail supply chain: on contractual form and coordination. Manage. Sci. 56 (2010) 571-589.

[3] G.P. Cachon and M.A. Lariviere, Supply chain coordination with revenue sharing contract: strengths and limitations. Manage. Sci. 51 (2005) 30-44.

[4] X. Chen and Z.J. Shen, An analysis of a supply chain with options contracts and service requirements. IISE Trans. 44 (2012) $805-819$.

[5] X. Chen, G. Hao, X. Li and K.F.C. Yiu, The impact of demand variability and transshipment on vendor's distribution policies under vendor managed inventory strategy. Int. J. Prod. Econ. 139 (2012) 42-48.

[6] X. Chen, G. Hao and L. Li, Channel coordination with a loss-averse retailer and option contracts. Int.l J. Prod. Econ. 150 (2014) $52-57$.

[7] T.M. Choi and S. Guo, Is a "free lunch" a good lunch? The performance of zero wholesale price-based supply-chain contracts. Eur. J. Oper. Res. 285 (2019) 237-246.

[8] C.J. Corbett, D. Zhou and C.S. Tang, Designing supply contracts: contract type and information asymmetry. Manage. Sci. 50 (2004) 550-559.

[9] P. Egri and J. Váncza, A distributed coordination mechanism for supply networks with asymmetric information. Eur. J. Oper. Res. 226 (2013) 452-460.

[10] Q. Feng and L.X. Lu, Supply chain contracting under competition: bilateral bargaining vs. Stackelberg. Prod. Oper. Manage. 22 (2013) 661-675.

[11] Q. Fu, S.X. Zhou, X.L. Chao and C.Y. Lee, Combined pricing and portfolio option procurement. Prod. Oper. Manage. 21 (2012) 361-377.

[12] B.C. Giri, J.K. Majhi and K. Chaudhuri, Coordination mechanisms of a three-layer supply chain under demand and supply risk uncertainties. RAIRO-Oper. Res. 55 (2021) S2593-S2617. 
[13] Y. He and J. Zhang, Random yield risk sharing in a two-echelon supply chain. Int. J. Prod. Res. 112 (2008) $769-781$.

[14] K. Inderfurth and J. Clemens, Supply chain coordination by risk-sharing contract under random production yield and deterministic demand. OR Spect. 36 (2014) 525-556.

[15] B. Keren, The single-period inventory problem: extension to random yield from the perspective of the supply chain. Omega 37 (2009) 801-810.

[16] M.A. Lariviere and E.L. Porteus, Selling to the newsvendor: an analysis of price-only contracts. Manuf. Serv. Oper. Manage. 3 (2001) 293-305.

[17] G.Y. Lee and R. Yang, Supply chain contracting with competing suppliers under asymmetric information. IISE Trans. 45 (2013) 25-52.

[18] L.Q. Li and K. Liu, Coordination contract design for the newsvendor model. Eur. J. Oper. Res. 283 (2019) $380-389$.

[19] J.B. Li and X.M. Luo, Supply chain coordination through capacity reservation contract and quantity flexibility contract. Omega-Int. J. Manage. S. 99 (2021) 102195.

[20] X.J. Li, J. Chen and X.Z. Ai, Contract design in a cross-sales supply chain with demand information asymmetry. Eur. J. Oper. Res. 275 (2019) 939-956.

[21] I. Moon, B.H. Ha and J. Kim, Inventory systems with variable capacity. Eur. J. Ind. Eng. 6 (2012) 68-86.

[22] K.S. Moorthy, Strategic decentralization in channels. Mark. Sci. 7 (1988) 335-355.

[23] O. Ozer and G. Raz, Supply chain sourcing under asymmetric information. Prod. Oper. Manage. 20 (2011) 92-115.

[24] B.A. Pasternack, Optimal pricing and return policies for perishable commodities. Mark. Sci. 4 (1985) $166-176$.

[25] C. Qiu and Y. Xu, Introductory pricing, market development and profit sharing. J. Rev. Pric. Manage. 14 (2015) $166-177$.

[26] J. Raju and Z.J. Zhang, Channel coordination in the presence of a dominant retailer. Mark. Sci. 24 (2005) $254-262$.

[27] T. Sawik, On the risk-averse optimization of service level in a supply chain under disruption risks. Int. J. Prod. Res. 54 (2016) 98-113.

[28] E. Simangunsong, L.C. Hendry and M. Stevenson, Supply-chain uncertainty: a review and theoretical foundation for future research. Int. J. Prod. Res. 50 (2012) 4493-4523.

[29] S.Y. Tang and P. Kouvelis, Pay-back-revenue-sharing contract in coordinating supply chains with random yield. Prod. Oper. Manage. 23 (2014) 2089-2102.

[30] O. Tang and S.N. Musa, Identifying risk issues and research advancements in supply chain risk management. Int. J. Prod. Econ. 133 (2011) 25-34.

[31] C.X. Wang, Random yield and uncertain demand in decentralized supply chains under the traditional and VMI arrangements. Int. J. Prod. Res. 47 (2009) 1955-1968.

[32] L. Xie, J.H. Ma and M. Goh, Supply chain coordination in the presence of uncertain yield and demand. Int. J. Prod. Res. 59 (2021) 4342-4358.

[33] B. Yan and Z. Chen, Pricing decision and coordination mechanism of dual-channel supply chain dominated by a risk-aversion retailer under demand disruption. RAIRO-Oper. Res. 55 (2021) 433-456.

[34] F. Ye, Q. Lin and Y. Li, Coordination for contract farming supply chain with stochastic yield and demand under CVaR criterion. Oper. Res. 20 (2020) 369-397.

[35] J. Zhang and J. Chen, Coordination of information sharing in a supply chain. Int. J. Prod. Econ. 143 (2013) $178-187$.

[36] S. Zhao and Q. Zhu, Remanufacturing supply chain coordination under the stochastic remanufacturability rate and the random demand. Ann. Oper. Res. 257 (2017) 661-695.

\section{Subscribe to Open (S2O) A fair and sustainable open access model}

This journal is currently published in open access under a Subscribe-to-Open model (S2O). S2O is a transformative model that aims to move subscription journals to open access. Open access is the free, immediate, online availability of research articles combined with the rights to use these articles fully in the digital environment. We are thankful to our subscribers and sponsors for making it possible to publish this journal in open access, free of charge for authors.

\section{Please help to maintain this journal in open access!}

Check that your library subscribes to the journal, or make a personal donation to the S2O programme, by contacting subscribers@edpsciences.org

More information, including a list of sponsors and a financial transparency report, available at: https://www. edpsciences.org/en/maths-s2o-programme 